\title{
Edusat: remote sensing as an educational resource. The use of data from the Copernicus program as an innovative teaching method for students, teachers, and researchers.
}

\author{
Carla Garcia-Lozano ${ }^{a}$, Laura Olivas $^{\mathrm{a}}$, Rosa Olivella ${ }^{\mathrm{a}}$, Anna Peliova ${ }^{\mathrm{a}}$, \\ carla.garcia@udg.edu, laura.olivas@udg.edu,rosa.olivella@udg.edu,an.peliova@gmail.com

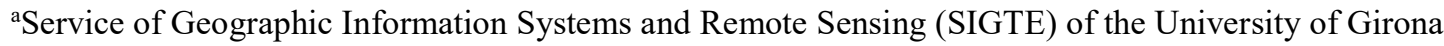

\begin{abstract}
The intensification in recent decades of scientific evidence on climate change and on the degradation of natural systems has led to increasing public awareness about the environment. In recent times, this commitment to respecting the natural environment has emerged strongly among young people. Through various platforms, entities, and slogans, students from all over the world, and belonging to different disciplines, are coming together to defend their right to have a planet that enjoys good environmental health.

The platform Edusat presented in this article aims to provide young people with empirical and quantitative learning tools to strengthen their ecology message. By means of remote sensing and through the data generated by the Copernicus program, an educational resource that analyzes the consequences of global environmental change is presented. In this context, remote sensing is a technological and transdisciplinary resource that provides young people with scientific arguments to censure the current relationship between human societies and nature.
\end{abstract}

Keywords: global environmental change, climate change, remote sensing, ecologism.

\section{Introduction: Remote sensing as an educational resource}

The social, economic and territorial dynamics that humanity has adopted since the First Industrial Revolution have led to the indiscriminate consumption of natural resources. The exploitation of these resources has put the well-being of the inhabitants of the planet Earth, as well as the physical systems that support it, at severe risk. This process has been described as "Global Environmental Change" and results in four well-known phenomena: pollution, biodiversity loss, change in land use and land cover, and climate change (Clark, 1988; Stern et al., 1992). All of these processes entail the degradation of the environment and threaten the prosperity of plants, animals and people on the planet
(Riebsame et al., 1994; De Chazal \& Rounsevell, 2009; Oliver \& Morecroft, 2014).

The scientific strength of the negative consequences of climate change, pollution or biodiversity loss further intensifies critical reflection among citizens. This sense of protest and struggle is especially intense among young people, who are fighting against the passivity of politicians on climate change mitigation policies. As such, these young people need to have the necessary competences in order to evaluate and disseminate the consequences of global environmental change in a critical and objective manner.

The availability of satellite imagery from around the world on a daily basis (depending on weather conditions) makes it easy to identify and monitor all of these natural phenomena and anthropic processes that involve notable changes to the land surface (Chuvieco, 2008). These images taken from space make it possible to study the evolution of natural and anthropic episodes such as wildfires, floods, melting glaciers, deforestation or urbanization (Trumbore et al., 2015).

Copernicus is the Earth observation program coordinated and managed by the European Commission and the European Environment Agency, with the aim of providing accurate and up-to-date information on six areas: climate change, security, emergency, atmosphere, marine environment, and land surface (Nieke, \& Rast, 2018).

All of this information is specially designed to provide a global view of the Earth's health, with the aim of helping governments to focus on environmental policies and to effectively monitor their implementation. Industries, organizations and researchers are also encouraged to make use of this data in conjunction with their own data in order to develop new functionalities and applications. Copernicus offers a complete set of open data, including the large volume of images captured from Sentinel satellites. This data is available through various websites, applications and services, and it is also designed for different user profiles, from highly specialized to less experienced ones. 


\subsection{Objectives}

Its theoretical foundations are in fact complex and not easily accessible for young people. The project presented in this paper aims to set out, in an educational and interactive way, the fundamentals of remote sensing in order to make the process of collecting and processing satellite images understandable. Therefore, the main objective of this learning material is to present remote sensing to a non-specialized audience and to offer a user-friendly tool for the analysis of land surface changes as well as a tool for the dissemination of results (Figure 1).

Three specific objectives stem from this main objective:

- To create an educational resource for young students.

- To design a teaching resource for educators in order to incorporate these competencies in curricula.

- To develop a transdisciplinary resource for young researchers that comes from various disciplines in order to analyze data and disseminate the results.

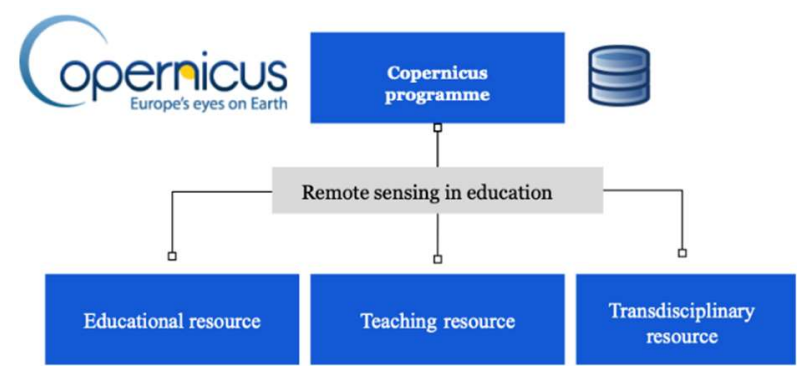

Figure 1. Specific objectives derived from implementing the remote sensing in education

\section{Description of the learning material}

In order to achieve the main objective, learning materials to make remote sensing accessible to young people have been created. Using satellite imagery, the consequences of global environmental change have been visually presented. The learning material has therefore been used to create a learning, teaching and transdisciplinary tool that revolves around the issue of environmental change. The teaching material is designed to be taught in two blocks (Figure 2):

a) Theoretical explanation of (i) what global environmental change is and its consequences (biodiversity loss, climate change, land-use changes, and land cover and pollution); and (ii) what remote sensing is (types of satellites, sensors, band combinations, uses, and applications). This section focuses in particular on the detection of land surface events resulting from the global environmental change of both natural or anthropic origin.

b) Practical exercises on the identification of natural phenomena or anthropic processes, such as forest fires, floods, droughts, deforestation, urbanization, glacier regression, air pollution and volcanic eruptions, among many others.

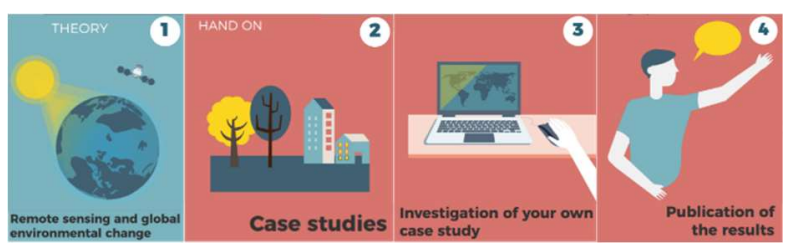

Figure 2. Structure of workshops.

\subsection{EO Browser: data access portal}

Several portals, applications, and services designed for different user profiles have been launched to access the satellite images of the Copernicus program. In this respect, the applications of the Sentinel Hub company stand out in particular. They hide the complexity of archiving, processing and distributing satellite imagery behind a set of standard web services that can be easily integrated into any desktop, web or mobile mapping application. This company developed the web application EO Browser (https://apps.sentinelhub.com/eo-browser), which makes it possible to view high-resolution images from Sentinel, Landsat and other satellites on a single website.

Furthermore, the EO Browser enables users to create comparisons or time lapses of satellite images so that the changes that have occurred in the territory can be easily identified by means of comparing several images taken on different dates.

Much of the potential of our educational project rests on the existence of an application such as EO Browser, which includes its own educational background (https://www.sentinel-hub.com/explore/education). For now, this application is an open-access tool that offers basic functionalities such as displaying the natural-color images of satellites; as well as advanced parameters of band combinations or the application of multiple indices through inter-band algorithms.

Additionally, temporary changes can be visualized through graphs, animations and comparisons between two or more images.

\subsection{Teaching activity: How to use satellite imagery to} identify the effects of global environmental change

\subsubsection{Duration of the activity}

The workshop can take from a minimum of one hour to a maximum 15 hours, depending on the availability and the profile of the group. Moreover, workshops can be 
compressed into a single session or be spread out over more than one, depending on the total number of hours.

The single-session workshops have a maximum duration of 4 hours and include (a) a brief theoretical explanation of what remote sensing is and (b) a practical demonstration of its potential: identification of fires, volcanic eruptions, floods, etc. During the practical block, students will learn first-hand how to use the resource with various up-to-date case studies.

Meanwhile, the workshop composed of several hours can be divided into a large number of classes. The number of sessions and their duration will depend on the availability and preferences of each group. For guidance purposes, the following model is proposed:

Session 1: Detailed explanation of satellites, sensors and their potential. Once the theoretical fundamentals have been established, the students' concerns will be identified and discussed.

Session 2: Many and varied case studies are used to show the possibilities of remote sensing in identifying natural and anthropic events such as wildfires, floods, droughts, deforestation or glacier recession. Furthermore, an explanation is provided of the EO Browser tool so that students can learn how to search for and process satellite images through this application. At the end of this session, students are split into themed groups and a topic is proposed for in-depth analysis in the next class.

Session 3: Analysis of the chosen natural or anthropic processes. In their groups, students will have to decide which satellites, band combinations or indicators best fit the chosen phenomenon. At the end of this session, the results of their research and the main conclusions should be clear.

Session 4: Presentation of the results of the different groups to their classmates. Discussion of the main conclusions during a question and answer session.

\subsubsection{Application cases}

Several case studies have been chosen to graphically and visually show the consequences of different natural and anthropic events. About 20 case studies have been documented belonging to various subject areas and concerning different geographical contexts (Table 1).

\begin{tabular}{ccc}
\hline Phenomenon & Case study & Date \\
\hline Forest fires & Kineta, Greece & July 23, \\
& & 2018 \\
\cline { 2 - 3 } & Nea Makri, Greece & July 23, \\
& & 2018 \\
\hline
\end{tabular}

\begin{tabular}{|c|c|c|}
\hline & Ribera d'Ebre, Spain & $\begin{array}{l}\text { June } 26 \text {, } \\
2019\end{array}$ \\
\hline & $\begin{array}{l}\text { Amazon, South } \\
\text { America }\end{array}$ & $\begin{array}{l}\text { Summer } \\
2019\end{array}$ \\
\hline & $\begin{array}{l}\text { Gran Canaria, Canary } \\
\text { Islands, Spain }\end{array}$ & $\begin{array}{l}\text { August } \\
17,2019\end{array}$ \\
\hline & East Coast of Australia & $\begin{array}{l}\text { December } \\
2019\end{array}$ \\
\hline \multirow[t]{3}{*}{$\begin{array}{l}\text { Volcanic } \\
\text { eruptions }\end{array}$} & Stromboli, Italy & $\begin{array}{l}\text { January } \\
2019\end{array}$ \\
\hline & Kilauea, Hawaii & $\begin{array}{c}\text { May } 3- \\
\text { August } \\
15,2018\end{array}$ \\
\hline & Etna, Italy & $\begin{array}{l}\text { October } \\
2019\end{array}$ \\
\hline \multirow[t]{2}{*}{ Floods } & Elx, Spain & $\begin{array}{l}\text { September } \\
12,2019\end{array}$ \\
\hline & $\begin{array}{l}\text { Temporary Glory, } \\
\text { Spain }\end{array}$ & $\begin{array}{l}\text { January } \\
20,2020\end{array}$ \\
\hline \multirow[t]{2}{*}{ Droughts } & Acuelo lagoon, Chile & $\begin{array}{c}\text { September } \\
2016- \\
\text { October } \\
2019\end{array}$ \\
\hline & $\begin{array}{c}\text { Aral Sea, } \\
\text { Uzbekistan/Kazakhstan }\end{array}$ & $\begin{array}{c}2016- \\
2019\end{array}$ \\
\hline \multirow[t]{3}{*}{$\begin{array}{l}\text { Glacier } \\
\text { regression }\end{array}$} & Vatnajökull, Island & $\begin{array}{c}2015- \\
2019\end{array}$ \\
\hline & $\begin{array}{c}\text { Amery Ice Bar, } \\
\text { Antarctica }\end{array}$ & $\begin{array}{c}\text { October } \\
2019- \\
\text { February } \\
2020\end{array}$ \\
\hline & Pine Island, Antarctica & $\begin{array}{l}\text { February } \\
2020\end{array}$ \\
\hline Deforestation & $\begin{array}{c}\text { San José de Chiquitos, } \\
\text { Bolivia }\end{array}$ & $\begin{array}{c}\text { August } \\
2015- \\
\text { November } \\
2020\end{array}$ \\
\hline \multirow[t]{2}{*}{ Urbanization } & Beijing airport, China & $\begin{array}{c}2014- \\
2019\end{array}$ \\
\hline & $\begin{array}{l}\text { Huoshenshan Hospital } \\
\text { in Wuhan, China }\end{array}$ & $\begin{array}{c}\text { January - } \\
\text { February } \\
2020\end{array}$ \\
\hline
\end{tabular}


Table 1. Case studies for territorial analysis based on remote sensing

For each case study the following is stated:

- The causes and consequences of the studied phenomenon (fire, flood, etc.)

- How Sentinel sensors can detect it: satellite types, indices, band combinations, ...

As such, in a truly practical manner, students can become familiar with the principles of remote sensing and how the Copernicus program can be used to detect real and up-to-date phenomena.

\subsection{Educational competences}

With the aim of achieving the objectives, a series of teaching competencies should be worked on:

- The use of emerging technologies, such as remote sensing, to analyze real-time territorial changes.

- The incorporation of a geographical point of view through remote sensing tools in order to analyze phenomena linked to global environmental change and, in particular, to climate change.

- To learn about objective and scientific resources with young people and teenagers.

- To introduce transdisciplinary materials and resources to work in different disciplines.

\section{Experiences gained}

Several experiences have been gained using this educational and didactic resource that endorse the proper functioning of the educational material presented here. The three experiences listed below show some specifically designed activities according to the time availability and profile of students.

\subsection{Workshop 1: Short workshop with high-school students}

Aimed at: 25 senior high-school students.

Duration: 1 hour.

Context: Visit the university to find out about geography studies and their real applications.

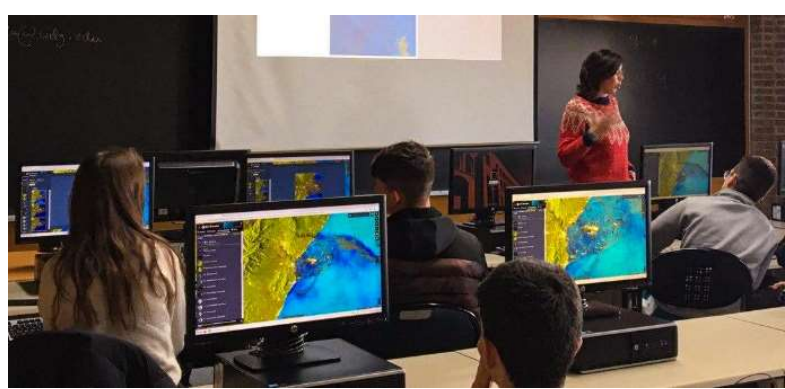

Figure 3. High school students observing the flooding in Ebro Delta after Storm Gloria with Sentinel 1

Details: The session included a brief explanation of the theoretical basis of remote sensing, as well as a series of case studies in which band combinations and terrain analysis were performed using a vegetation index, band combinations and enhanced visualization of the Sentinel 1 satellite. The case studies of the application were the wildfire in the Ribera d'Ebre region (Catalonia), the recent fires in Amazonia and Australia, and the effects of Storm Gloria on the Catalan coastline (Figure 3).

\subsection{Workshop 2: Long workshop with first-year high-school students}

Target: 20 first-year high-school students from the Foundation for Helping Children and Youth with High Capabilities (FANJAC).

Duration: 3 hours.

Context: Extra-curricular activity organized by FANJAC.

Details: Despite the high profile of students and/or their intellectual abilities, the young age of the members (between 11 and 13 years old) made it necessary to guide and direct the session in a very detailed manner. The first hour focused on the theoretical basis of remote sensing and the fundamentals of global environmental change. For the second and third hours, students worked in pairs with the EO Browser on case studies such as recession of glaciers (Figure 4), fires in Australia, fires in Amazonia or flooding in the Ebre Delta after Storm Gloria.

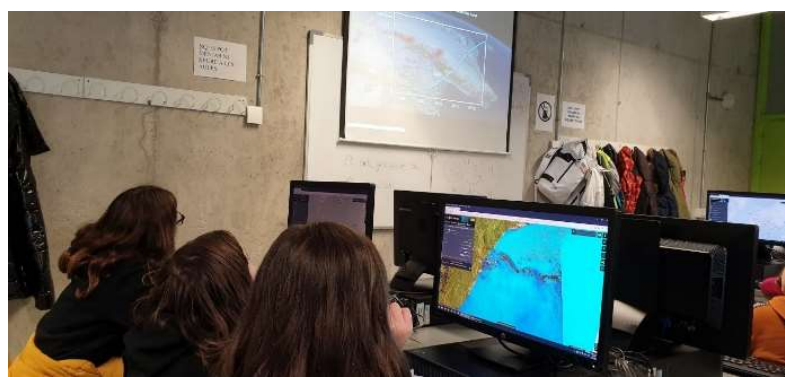


Figure 4. First-year high school students attending an audiovisual made by European Spatial Agency (ESA) about the recession in the Greenland glaciers

\subsection{Workshop 3: Several long sessions with high- school students}

Target: 20 students aged between 13 and 17 years old.

Duration: 4 sessions of 3 hours each.

Context: Extra-curricular activity organized by FANJAC.

Details: In this case, given the special characteristics of the students (with high ability and motivation), an initial session was held that focused exclusively on the principles of remote sensing. This was a session with a theoretical basis but which promoted student participation. At the end of this session, the students proposed a set of possible topics to identify events through remote sensing.

The second session focused on practical work. The students were introduced to EO Browser functionalities through practical cases that they had to work through on their computers. After creating work groups of between two and four members, the analysis of topics was carried out (Figure 5).

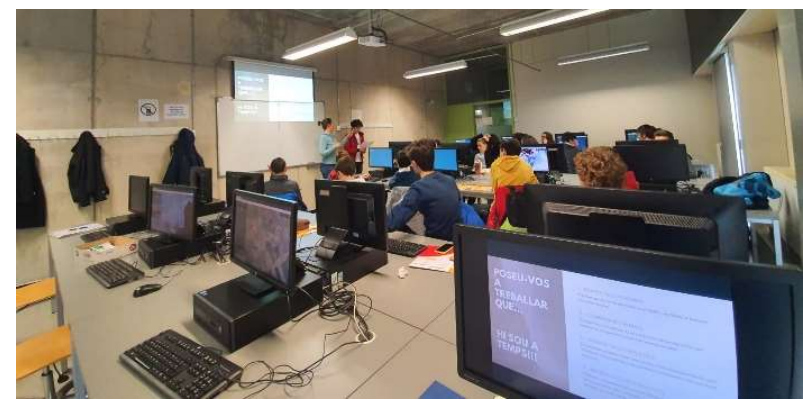

Figure 5. High-school students discussing the viability of analysis of topics previously proposed in groups

The third session was devoted to in-depth work on each chosen topic, identifying a specific phenomenon: time factor, causes, characteristics. The following six projects were established:

- Evolution and consequences of the Kilauea Volcano, Hawaii.

- Air pollution: comparison between China and the Iberian Peninsula.

- Identification of plastics in the ocean.

- Urban growth in developing and developed countries: Ulan Bator, Barcelona, and New Delhi.

- Sediment flow in the nearshore before and after a storm event.
Students were also shown a tool to communicate their results based on the Story Map.

The last session has still not been held. It is scheduled for April 18, when the results will be presented to the students' classmates, families and teachers in a closing plenary session.

\section{Platform Edusat}

To fully achieve the specific objectives set out in this paper, we designed an educational platform that is open and available to the entire educational community (Figure 6): www.edu-sat.com. As such, students, teachers, and researchers have access to a self-learning resource in which the potential of remote sensing, applied in different case studies, is set out.

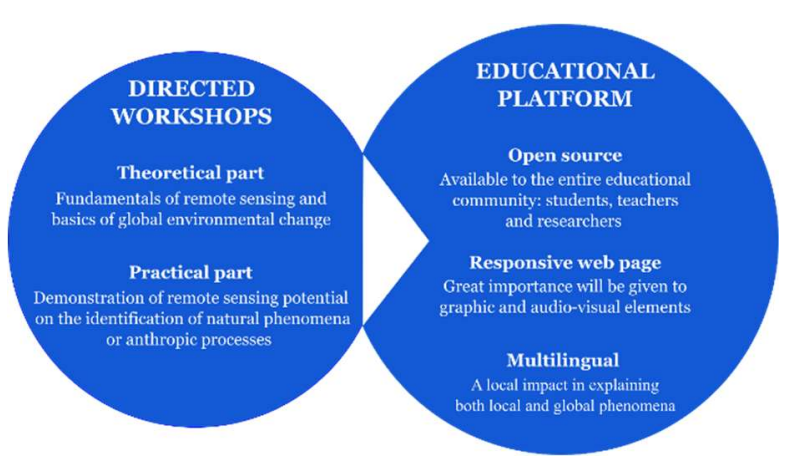

Figure 6. Publish the learning material on an educational platform will contribute to fully achieve the objectives set out in this paper

The web portal contains different menus: basic principles of remote sensing, case studies (explaining various natural and anthropological phenomena), exercises to work on with the EO Browser and a manual for teachers. The platform has a responsive web page format and great importance is given to graphic and audio-visual elements (images, videos, time lapses, maps, gifs, etc.) in order to clearly and understandably explain global environmental change.

The website is multilingual (Catalan, Spanish and English), although the initial intention is to exploit the resource in a local context. The platform is a resource that aims to have a local impact in explaining both local and global phenomena.

The goal of making the materials openly available is to empower users to learn a resource, regardless of whether or not they have completed the courses we offer. The dissemination of the materials enable anyone to become 
familiar with the applications and the usefulness of satellite imagery.

In this first version of this website, we have developed nine case studies that allow us to demonstrate the usefulness of satellite images to observe and analyze the current phenomena of global environmental change. The case studies are accompanied by videos where the step by step is displayed in order to get the results we show for each phenomenon studied so that the user can get the same results using videos as a fast consumption guide.

This platform has been developed with the funding of Cordinet program from the European Commission, as well as local funding from the University of Girona. The next step will be to add more case studies as the project becomes funded, as well as to collaborate with European Partners to be able to give an international dimension to the project.

\section{Conclusions}

Far from being a discipline reserved for specialists and reduced to a select group of professionals, remote sensing is an affordable and highly educational tool when it comes to showing young people, educators and scientists another way to study reality and disseminate the results. Thanks to the EU Copernicus program and to some of the tools that have been promoted around it (EO Browser), remote sensing is made accessible to students, educators and researchers.

In conclusion, the didactic and educational platform presents an objective and analytical vision regarding territorial processes resulting from global environmental change. Through remote sensing, the ecological discourse emerging among young people is given empirical and experimental content.

\section{References}

Clark, W.C.: The human dimensions of global environment change. In: Committee on Global Change. Towards an Understanding of Global Change. National Academy Press, Washington, DC. 1998

Chuvieco, E.: Earth observation of global change: The role of satellite remote sensing in monitoring the global environment. Springer. 2008

De Chazal, J., \& Rounsevell, M. D.: Land-use and climate change within assessments of biodiversity change: a review. Global Environmental Change, 19(2), 306-315. 2009
Nieke, J., \& Rast, M.: Towards the copernicus hyperspectral imaging mission for the environment (CHIME). In IGARSS 2018-2018 IEEE International Geoscience and Remote Sensing Symposium (pp. $157-$ 159). IEEE. 2018

Oliver, T. H., \& Morecroft, M. D.: Interactions between climate change and land use change on biodiversity: attribution problems, risks, and opportunities. Wiley Interdisciplinary Reviews: Climate Change, 5(3), 317335. 2014

Riebsame, W. E., Meyer, W. B., \& Turner, B. L.: Modeling land use and cover as part of global environmental change. Climatic change, 28(1-2), 45-64. 1994

Stern, P. C., Young, O. R., \& Druckman, D. E.: Global environmental change: Understanding the human dimensions. National Academy Press. 1992

Trumbore, S., Brando, P., \& Hartmann, H.: Forest health and global change. Science, 349(6250), 814-818. 2015 